\title{
Impact of Conductor Surface Type and Rain Intensity on HVDC Corona Losses
}

\section{Journal Article}

Author(s):

Pfeiffer, Martin D.; Franck, Christian (i)

Publication date:

2015-10

Permanent link:

https://doi.org/10.3929/ethz-b-000104876

Rights / license:

In Copyright - Non-Commercial Use Permitted

Originally published in:

IEEE Transactions on Power Delivery 30(5), https://doi.org/10.1109/TPWRD.2015.2424315 


\title{
Impact of Conductor Surface Type and Rain Intensity on HVDC Corona Losses
}

\author{
Martin Pfeiffer and Christian M. Franck, Senior Member, IEEE
}

\begin{abstract}
This paper presents the results of a series of indoor laboratory experiments carried out on DC energized overhead conductors subjected to simulated rainfall. In a first set of experiments, the impact of rain intensity on the corona onset voltage and total corona losses was investigated. With regard to the onset voltage, no significant impact was observed, whereas a weak positive correlation with total corona losses could be established. In a second set of experiments, the impact of different conductor types on the same two quantities was examined. The most notable result is that the combined use of $\mathrm{Z}$-profiled-strands and sand-blasted surfaces lead to reductions in the total corona current of around $29 \%$ and $42 \%$, for positive and negative polarity respectively. The corresponding reduction of ground level ion currents and ion coupling with parallel conductors is expected to be of the same order of magnitude.
\end{abstract}

Index Terms - HVDC, corona, ion current, rain

\section{INTRODUCTION}

$\mathbf{F}$ OUL weather, in particular rain, has been shown to constitute the worst case scenario with regard to total corona losses (CL) of HVDC overhead transmission systems [1], [2], [3]. Effects that are directly linked to total CL are ground level DC ion current densities and ground level DC electric field enhancements. The combination of high DC fields and DC ion currents has been shown to significantly reduce human perception and annoyance thresholds [4]. Furthermore, the electrification of people or objects can lead to undesirable spark discharges, for example from an umbrella to a person [5], [6]. It is therefore in the public's interest to fully investigate DC corona production mechanisms and mitigation options. While rain increases total CL and ion currents in HVDC transmission systems, it has been shown to decrease audible noise and radio interference [7]. This is in contrast to HVAC transmission systems in which both, CL and audible noise, increase during rain.

DC ion currents also have implications for hybrid $\mathrm{AC} / \mathrm{DC}$ transmission systems, i.e. transmission towers that carry both AC and DC conductors. This technology has been under discussion for several decades [8], [9], [10] and is receiving renewed attention in recent years due to active research into the conversion of existing multi-circuit AC towers to hybrid AC/DC systems in Germany [11], [12]. Depending on the tower geometry and the relative

This work was financially supported by Amprion GmbH, Germany.

The authors are with the Power Systems and High Voltage Laboratories, ETH Zurich, Zurich 8092, Switzerland (e-mail: mpfeiffer@ethz.ch; cfranck@ethz.ch). orientation of conductors, ions produced through corona at the DC poles can drift towards $\mathrm{AC}$ conductors and cause DC current components in AC phases. This could potentially lead to adverse effects in transformers due to an increase of magnetization currents [13]. Like the ground level ion current density, this effect is also directly linked to total CL and is therefore most severe during rain conditions.

Measurements on operational HVDC systems as well as on test lines have been used in the past to study the impact of rain on HVDC corona phenomena.

With regard to operational lines, the most extensive studies have been carried out on the following three projects: the Nelson River line operated by Manitoba Hydro [14], [15], the Pacific DC Intertie operated by the Bonneville Power Administration [16] and the Quebec - New England line operated by Hydro-Quebec (measurement results summarized in [17]). The available data focuses primarily on ground-level phenomena such as ioncurrent densities, space charge enhanced electric fields, radio interference and audible noise. Data presented in [16] found that ground level ion current densities and electric fields were highest in rain but also asserts that a more detailed comparison of different foul weather conditions is difficult due to the simultaneous occurrence of multiple effects (e.g. rain and wind). None of the other publications on operational lines presents detailed information on the impact of rain.

More data is available on the impact of rain based on test lines and corona cage experiments. Studies on a test line by ASEA in Sweden in the early 1960s have identified a positive variation of corona power losses with rain intensity [7]. Since the method of arriving at the different rain intensities was not specified, it can be assumed that it is based on isolated instances of natural rainfall. The study considered the impact of differences in the number of sub-conductors per bundle but did not investigate different conductor surface types. In similar experiments conducted by the National Research Council in Canada, it was shown that CL in wet conditions are approximately a factor of 4 higher compared to dry conditions [18]. No differentiation between rain intensities or conductor types were made. In subsequent years results were presented for a test line by the Bonneville Power Administration [19], [20], [21], [22]. The data supports the finding in [18] that CL are approximately 3-5 times larger in rain compared to fair weather [20], [22]. A description of HVDC CL as a function of rain intensity is presented in [2], in which data from a test line in Germany is analyzed. The presented function 
shows a sharp increase of CL with rain intensity and a subsequent trend towards a saturation (i.e. only minor increases of CL with increased rain intensity). Further data that supports the increase of CL with rain is available in studies by the research institute of Hydro-Quebec, IREQ [23], [24], [25].

It can be summarized that the available literature contains very strong evidence that HVDC CL are highest during rain. A more in-depth investigation of this worstcase, however, is missing. The role of the rain intensity, for example, has only briefly been reported in [7], [2] and was not based on controlled conditions. Furthermore, in both cases it is not clear how many events were used in producing the presented data. Finally, to the best of the authors knowledge, mitigation options for HVDC CL during rain, such as the use of alternative conductor surface types, have not yet been presented in the literature. The aim of this publication is to contribute controlled results for the impact of the rain intensity and the conductor surface type on HVDC CL under rain.

\section{EXPERIMENT SET-UP}

\section{A. Geometric Properties}

For Experiment 1 (Section III: Impact of Rain Intensity), the test-object was a $6.4 \mathrm{~m}$ long four-conductor bundle with a nominal sub-conductor spacing of $0.4 \mathrm{~m}$. The sub-conductors were of the ACSR (Aluminium Conductor Steel Reinforced) type with a nominal diamter of $22 \mathrm{~mm}$ and 15 round sub-conductors on the outside layer. For Experiment 2 (Section IV: Impact of Conductor Type), the four-conductor bundle was replaced with single conductors of various types (described below). A schematic side-view of the conductor suspension and rain simulation hardware is shown in Figure 1.

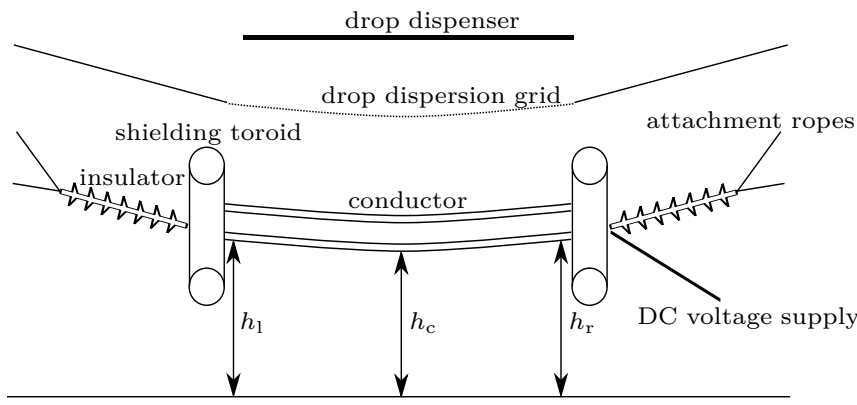

Fig. 1: Schematic side view of experimental setup (not to scale).

For Experiment 1 (Section III), the dimensions $h_{\mathrm{l}}, h_{\mathrm{c}}$ and $h_{\mathrm{r}}$ were $100.5,82$ and $100 \mathrm{~cm}$, respectively. For Experiment 2 (Section IV), $h_{\mathrm{c}}$ was adjusted to $94 \mathrm{~cm}$, while $h_{\mathrm{l}}$ and $h_{\mathrm{r}}$ varried between 103 and $108 \mathrm{~cm}$ due to slight differences in the lengths of the different conductor types. For the larger diameter conductors (cf. Table II) $h_{\mathrm{l}}$ and $h_{\mathrm{r}}$ were in the range of 111 and $115.5 \mathrm{~cm}$. In parallel to the length of the conductor, $2 \mathrm{~m}$ high grounded fences bounded the high voltage area. On one side of the conductor the fence was spaced $150 \mathrm{~cm}$ from the axis of the conductor and on the other side about $235 \mathrm{~cm}$.

The maximum conductor surface field strength values given in the results sections are based on FEM simulations of the Laplace field of the $2 \mathrm{D}$ cross-section at the point of maximum sag, i.e. at $h_{\mathrm{c}}$.

3D-FEM simulations showed that the shielding toroids' impact extends to approximately $1.2 \mathrm{~m}$ of the conductor length on each end. Therefore, the effective conductor length over which corona activity takes place is assumed to be $4 \mathrm{~m}$. The rain simulator was set-up in such a way that only in this section large rain drops formed. Although some mist extended slightly beyond this range, observations through a UV camera indicated that the corona activity was indeed limited to this range.

\section{B. Supply and Measurement of Electrical Quantities}

The DC voltage was applied with a two-stage Greinacher cascade capable of producing up to $\pm 280 \mathrm{kV}$. The voltage was measured on the high voltage side with a resistive voltage divider. An analogue-to-digital converter was used to read the voltages into the measurement PC. A programmable AC voltage source $(0-220 \mathrm{~V})$ was used to feed a high voltage transformer $(220 \mathrm{~V}$ primary corresponding to $100 \mathrm{kV}$ secondary).

The corona current was measured with a system developed by the ETH spin-off Kametech AG. The system measures the voltage drop across a remotely adjustable resistor that is placed in series between the DC cascade and the test object. The results are transmitted to the measurement $\mathrm{PC}$ via optical cables. All quantities were measured with a repetition rate of $1 \mathrm{~Hz}$. For the total corona current a low-pass filter with a cut-off frequency of $1 \mathrm{~Hz}$ was used.

\section{Rainfall Simulation}

The rainfall simulator was constructed by Straumann [26] based on the design presented in [27]. Water is supplied to an approximately $4 \times 0.6 \mathrm{~m}$ drop production array located at the $10 \mathrm{~m}$ high ceiling via the mains water supply. The aray is fitted with approximately 500 hollow needles from which drops fall towards ground periodically. The falling drops are dispersed with a grounded grid suspended $4 \mathrm{~m}$ above ground (cf. Figure 1). This reduces the mean drop size and increases the drop size distribution, bringing it closer to the characteristics of natural rainfall [27]. At ground level the water is collected in an $8 \times 3 \times 0.1 \mathrm{~m}$ pool. A throttling valve is used to adjust the rain intensity. The flow rate of the water going into the system is digitally recorded. In the experiments presented in Section III, five different rain intensities were investigated as shown in Table I. The "light rain" intensity is the lowest intensity that could reliably be reproduced given the sensitivity of the flow-meter.

\section{Conductor Types}

For Experiment 2 presented in Section IV, five different conductor types were investigated. Their key parameters 
TABLE I: Definition of rain intensities and ground measurements.

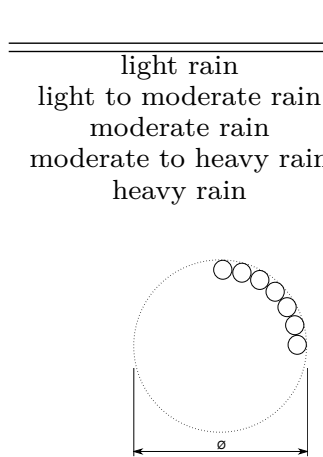

(a) round $\varnothing$ Measured $\mathrm{mm} / \mathrm{h}$

9.8

14.3

22.2

36.5

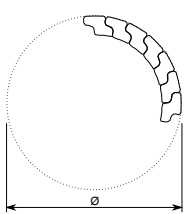

(b) Z
Fig. 2: Schematic illustration of the two investigated outer strand types. See Table II for nominal diameters.

are given in Table II. The conductor used in the fourconductor bundle in Section III is of type A.

The column "Sand Blasted" refers to whether or not the conductor has undergone a surface treatment in which its roughness, and thereby its hydrophilicity, were increased. In [28], [26], [29] it was shown that this type of surface treatment reduces corona generated audible noise on HVAC conductors. This is because a higher hydrophilicity reduces the field enhancing effects of raindrops on conductor surfaces. In [29] the fact that water drops drip off more readily on hydrophilic conductors and thus lead to the formation of fewer and flatter water drops is stated as the reason for lower AC corona effects and tonal emissions.

The column "Outer Strand Profile" refers to the shape of the conductor strands in the outer layer of the conductor. The two investigated types are schematically shown in Figure 2.

With regard to maximum single conductor or bundle conductor surface gradients, three different concepts are defined as follows:

- $E_{\text {max }, \text { ideal, the maximum surface gradient considering }}$ perfectly smooth, dry and round conductors.

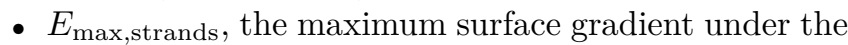
same conditions as $E_{\max \text {,ideal }}$ but taking into account the shape of the outer strands of the conductors

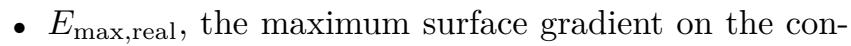
ductor taking into account field disturbances caused by rain drops

TABLE II: Conductor types and key parameters.

\begin{tabular}{cccc} 
& $\begin{array}{c}\text { Nominal } \\
\varnothing(\mathrm{mm})\end{array}$ & $\begin{array}{c}\text { Outer Strand } \\
\text { Profile }\end{array}$ & $\begin{array}{c}\text { Sand } \\
\text { Blasted }\end{array}$ \\
\hline \hline A & 22 & Round & No \\
B & 22 & Round & Yes \\
C & 22 & Z & No \\
D & 22 & Z & Yes \\
E & 32 & Round & No \\
F & 32 & Z & No \\
G & 32 & Z & Yes
\end{tabular}

\section{EXPERIMENT 1: IMPACT OF RAIN INTENSITY}

\section{A. Experimental Procedure}

The experimental procedure for these measurements was as follows:

1) Rain intensity was set to lowest level and corona current on energized conductor was measured for approximately 60 minutes to ensure that the system is in steady state.

2) A constant voltage measurement was conducted for a period of 5 minutes at an AC supply voltage of $200 \mathrm{~V}$ AC, which correponds to a DC voltage between 201 and $206 \mathrm{kV}$ for the highest and lowest rain intensity, respectively. This corresponds to a maximum conductor surface field strength range of 24.7 to $25.3 \mathrm{kV} / \mathrm{cm}\left(E_{\max \text {,ideal }}\right)$, which is a realistic value for the maximum surface field strength of $400 \mathrm{kV}$ HVDC conductors on actual towers.

3) The voltage was reduced to zero at a rate of approximately $2 \mathrm{kV} / \mathrm{s}$.

4) A corona onset voltage test was conducted by increasing the AC supply voltage from 0 to $215 \mathrm{~V}$ in steps of $5 \mathrm{~V}$ (corresponding to approximately $5 \mathrm{kV}$ increases of the DC voltage of the line). Each voltage level was held for 5 seconds.

5) The voltage was reduced to zero at a rate of approximately $2 \mathrm{kV} / \mathrm{s}$.

6) Steps 2 and 4 were repeated for the opposite polarity.

7) The rain intensity was increased to the next highest level and a 10 minute pause was obeyed.

8) The procedure was repeated for the new rain intensity from step 2. Starting from the second rain intensity the duration of the constant voltage measurement was increased to 10 minutes in order to ensure that a steady state had formed.

One weakness of the described procedure is that the DC voltages corresponding to a given controlled AC supply voltage decreased slightly with an increase in the load (i.e. corona) current. At the time of the experiments no feedback controller for the secondary voltage had been implemented. Another weakness of the procedure is that the water level in the collecting pool was not controlled and was also not systematically recorded. In certain measurements it may have been up to approximately $2 \mathrm{~cm}$ higher than in others, leading to a lower effective value of $h_{\mathrm{c}}$.

\section{B. Results}

1) Constant Voltage Measurements: Figure 3 shows the total corona current of the constant voltage measurements as a function of the applied rain intensity. For both polarities, a positive correlation can be observed between rain intensity and corona current, despite a number of outliers. The figure also indicates the approximate order of magnitude of the corona current for dry conductors. The factor between the dry corona current and that for the lowest rain intensity is approximately 20 for both 


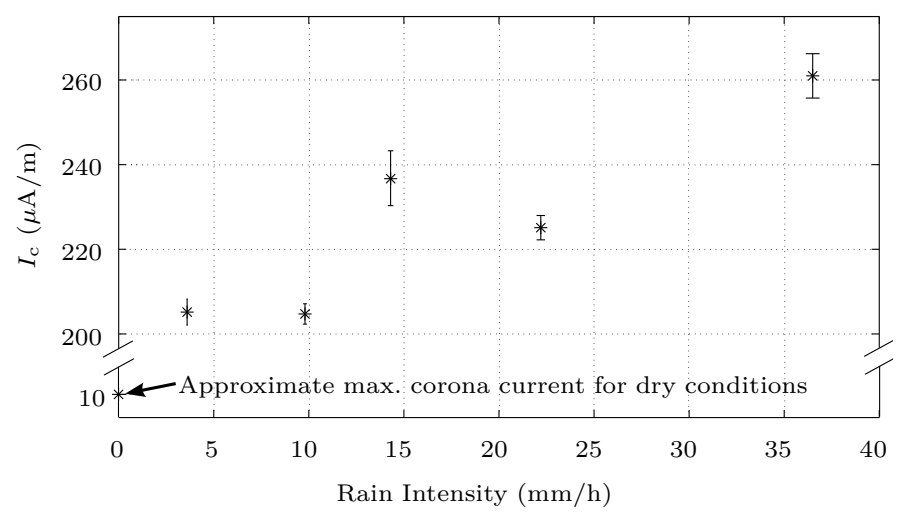

(a) Positive polarity

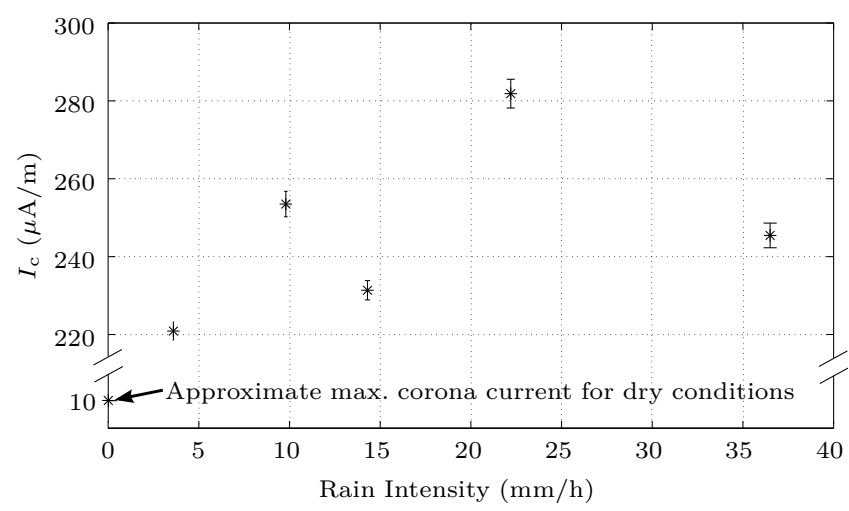

(b) Negative polarity

Fig. 3: Magnitude of total corona current as a function of rain intensity (voltage constant at $203.5 \mathrm{kV} \pm 2.5 \mathrm{kV}$ and $-202 \mathrm{kV} \pm 3 \mathrm{kV}$, for positive and negative polarity respectively).

polarities. The current for negative polarity is about $8 \%$ higher than that for positive polarity (averaged across all rain intensities).

2) Corona Onset Measurements: The results of the corona onset measurements for different rain intensities are presented in Figure 4. The errorbars indicate the standard deviation of the current within each voltage step. For comparison, results for dry and clean conductors are also given. It can be seen that for this condition even at the highest applied voltages, corona currents are negligible compared to the case in rain.

For rain conditions, measurable non-zero currents are detected starting from voltages of approximately $60 \mathrm{kV}$. The corona currents then appear to increase linearly up to about $100 \mathrm{kV}$ at which point their rate of rise increases noticeably and the currents increase exponentially with increasing voltage.

For voltages just above the corona onset, the difference in the corona currents for the different rain intensities is negligible. Significant differences only begin to emerge at voltages above approximately $160 \mathrm{kV}$. Between $160 \mathrm{kV}$ and the maximum DC voltage the relative corona current differences between the different rain intensities largely correlate with the results obtained for the constant voltage

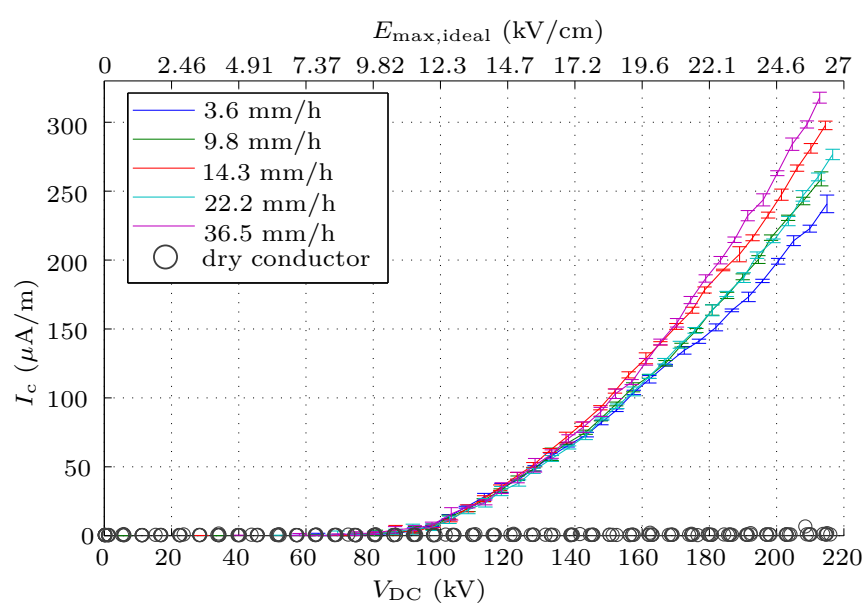

(a) Positive polarity

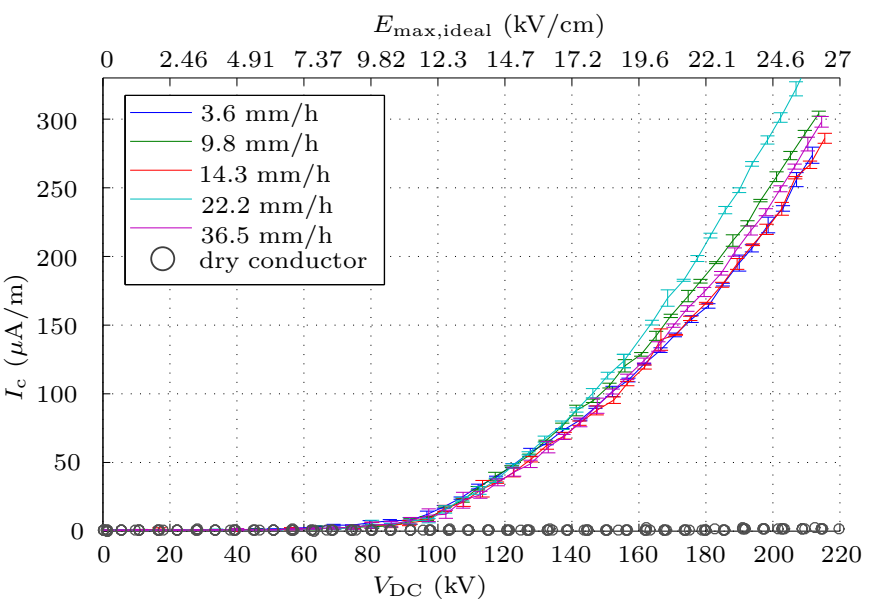

(b) Negative polarity

Fig. 4: Total corona current magnitude as a function of applied DC voltage

measurements.

Defining a unique onset voltage is challenging since different criteria (e.g. corona currents, light or sound emissions) can in principal be used. In this publication a method based on a critical corona current threshold is employed. Using a threshold of $5 \mu \mathrm{A} / \mathrm{m}$ for the bundle conductor measurements, the onset voltage for all rain intensities is approximately $86 \mathrm{kV}\left(E_{\text {max }, \text { ideal }}=10.55 \mathrm{kV} / \mathrm{cm}\right)$ for negative polarity and $92 \mathrm{kV}\left(E_{\text {max,ideal }}=11.3 \mathrm{kV} / \mathrm{cm}\right)$ for positive polarity.

\section{Discussion}

1) Constant Voltage Measurements: The drastic increase of total corona current between no-rain and rain conditions that is shown in Figure 3 is congruent with existing field data collected on various HVDC lines [18], [20], [2], [22], [3], [16]. The factor found in this laboratory study, however, is larger than those presented in field 
experiments [18], [20], [22]. This is due to the fact that pollution on outdoor lines leads to higher dry CL.

The additional increase of corona intensity with increasing rain intensity is also congruent with previously reported evidence [2]. Based on their observations carried out on a $400 \mathrm{kV}$ HVDC test line [2] noted that moisture on the conductors increased corona losses drastically while additional increases with an increase in rain intensity were described as moderate. While [2] did not provide a theory for this effect, it seems likely that an increase in rain intensity leads to faster replenishing of large rain drops on the lower side of the conductor. According to [1] the corona pulse repetition rate is the primary determining factor for total corona losses. The pulse repetition rate, on the other hand, was shown by [1] to be highest on large drops that deform in the electric field to form so-called Taylor cones [30], [31], [32]. Since these drops periodically shed water due to mechanical instabilities, it is plausible that a higher rain intensity leads to a higher time-averaged presence of such drops.

The outliers observed in Figure 3 are an indication for the presence of random error sources, most likely due to slow transient processes related to changing water drop shape and distribution patterns. In separate measurements it was observed that even after one hour of constant rain intensity, seemingly random increases and decreases of the corona current can still occur. For negative polarity one such outlier is the total corona current measured for the highest rain intensity, which does not follow the described trend and is in fact lower than the current measured for the second lowest rain intensity. These random errors weaken the established trend; a general tendency can nevertheless be observed.

The presented results confirm the already established fact that the total corona losses of negative DC poles is slightly higher than those of positive poles [18], [1], [33]. The mean current for negative polarity is about $8 \%$ higher than that for positive polarity. This can be attributed to the somewhat higher average ion mobility of negative ions [34]. Furthermore, it is well established that the onset of negative corona occurs at slightly lower voltages compared to that of positive corona. This is because for positive polarity electron avalanches have to start in the gas volume surrounding the conductor, whereas for negative polarity they can start at the location of the highest field, i.e. the surfaces of the conductor or rain drops.

Because the applied DC voltage decreases slightly with rain intensity (see Section III-A), the positive correlation between rain intensity and corona losses would probably be slightly higher for an actual HVDC transmission line, in which corona losses would not lead to a noticeable voltage drop.

2) Corona Onset Measurements: An explanation for the regime change observed at around $100 \mathrm{kV}$ in Figure 4 could be the delayed corona onset of the upper two sub-conductors which have lower surface field strengths. Based on an analysis of $E_{\text {max,ideal }}$, the upper two subconductors reach the field strength that the lower two subconductors have at $60 \mathrm{kV}$ only at a voltage of around $67 \mathrm{kV}$. The relative difference in $E_{\text {max,real }}$ between the lower and upper sub-conductors could, however, differ even more. Nevertheless, the theory that this is responsible for the observed regime change is still very speculative. UV observations to locate the corona sources could be used for further investigations. Another explanation could be related to changing corona characteristics of suspended rain drops as they change shape in the electric field [32].

A possible explanation for the divergence of the curves in Figure 4 starting from voltages of approximately $160 \mathrm{kV}$ is that corona activity may only start influencing rain drop removal rates at higher field strengths when stresses on the drops become high enough to cause mechanical instabilities. If the removal rate is influenced by the field, then it follows that the rate at which drops are replenished, i.e. the rain intensity, influences the total number and size of drops in the steady state and it is likely that these parameters in return determine the total corona current, as mentioned in Section III-C1.

\section{Experiment 2: Impact of Conductor Type}

\section{A. Experimental Procedure}

For each conductor type the following experimental procedure was carried out for positive as well as negative polarity:

1) The dry conductors were cleaned with alcohol and a lint-free cloth. The voltage was then set to $\pm 135 \mathrm{kV}$ to ensure that under dry conditions no corona activity is present. If the corona current at this voltage exceeded $0.25 \mu \mathrm{A} / \mathrm{m}$, the cleaning procedure was repeated. This sequence was repeated until the threshold was no longer exceeded.

2) The rain intensity was set to approximately $7.5 \mathrm{~mm} / \mathrm{h}$ and the corona current on the energized conductor $( \pm 135 \mathrm{kV})$ was measured for 20 to 30 minutes to ensure a steady state. The voltage was then ramped back down to $0 \mathrm{kV}$ at a rate of approximately $2 \mathrm{kV} / \mathrm{s}$

3) A corona onset measurement in which the voltage was ramped up from $20 \mathrm{kV}$ to approximately $100 \mathrm{kV}$ in steps of $5 \mathrm{kV}$ was carried out. Each voltage step was held for 60 seconds.

4) A 10 minute constant voltage measurement at $\pm 135 \mathrm{kV}$ was carried out. This corresponds to a maximum conductor surface gradient, $E_{\text {max,ideal }}$, of approximately $25 \mathrm{kV} / \mathrm{cm}$ for conductors A through $\mathrm{D}$ and $19 \mathrm{kV} / \mathrm{cm}$ for conductors $\mathrm{E}, \mathrm{F}$ and $\mathrm{G}$.

\section{B. Results}

1) Constant Voltage Measurements: The resulting mean corona currents recorded during the 10 minute constant voltage measurements for the seven conductor types is presented in Figure 5. The values are normalized against the maximum of $72.4 \mu \mathrm{A} / \mathrm{m}$ which occurred for conductor type A (negative polarity). 


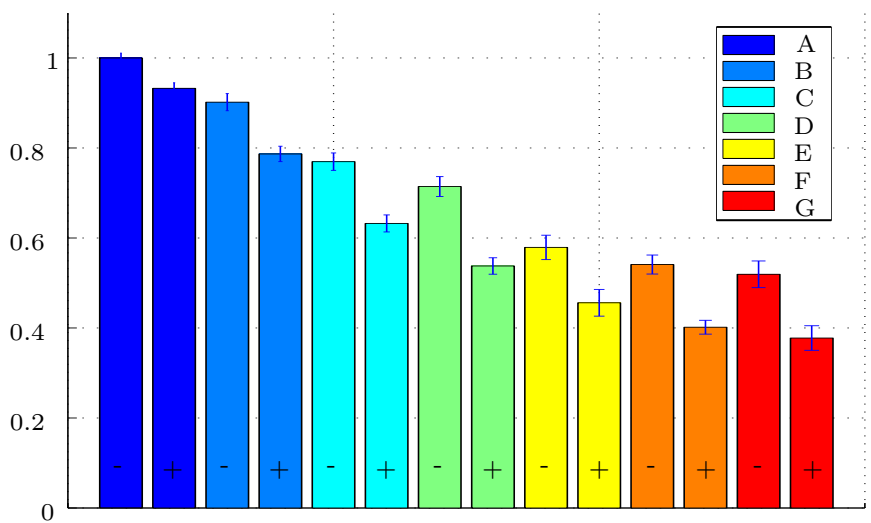

Fig. 5: Total corona current magnitudes at $135 \mathrm{kV}$. Normalized against maximum of $72.4 \mu \mathrm{A} / \mathrm{m}$.

For all seven conductor types, the corona current is between $7 \%$ and $37 \%$ higher for negative polarity compared to positive polarity. This is congruent with the results presented in Section III.

The most notable result is that very significant differences exist in the total corona currents between the different conductor types. The untreated standard $22 \mathrm{~mm}$ diameter conductor with round strand profiles (Type A) leads to the highest corona currents whereas the sandblasted $32 \mathrm{~mm}$ diameter Z-profile conductor (Type G) leads to the lowest values. Compared to conductor A, conductor $\mathrm{G}$ represents a $48.1 \%$ and $59.5 \%$ reduction in total corona current, for negative and positive polarity respectively. The total corona current measured for the remaining five conductor types falls in between these two boundaries. The following general trends can be concluded from the presented data:

- Conductors with a larger diameter show lower total corona currents compared to their thinner counterpart. The reduction for positive polarity for the pairs $\mathrm{A} \& \mathrm{E}, \mathrm{C} \& \mathrm{~F}$ and $\mathrm{D} \& \mathrm{G}$ is $51 \%, 37 \%$ and $30 \%$, respectively (average 39\%). The corresponding reductions for negative polarity are $42 \%, 30 \%$ and $27 \%$, respectively (average $33 \%$ ). The combined average reduction is $36 \%$.

- Conductors with sand-blasted surfaces show lower total corona currents compared to their non-treated counterpart. The reduction for positive polarity for the pairs $\mathrm{A} \& \mathrm{~B}, \mathrm{C} \& \mathrm{D}$ and $\mathrm{F} \& \mathrm{G}$ is $16 \%, 15 \%$ and $6 \%$, respectively. The corresponding reductions for negative polarity are $10 \%, 7 \%$ and $4 \%$, respectively.

- Conductors with Z-profiled outer strands show lower total corona currents compared to their counterpart with round outer strands. The reduction for positive polarity for the pairs $\mathrm{A} \& \mathrm{C}$ and $\mathrm{B} \& \mathrm{D}$ and $\mathrm{E} \& \mathrm{~F}$ is $32 \%, 32 \%$ and $12 \%$, respectively. The corresponding reductions for negative polarity are $23 \%, 21 \%$ and $7 \%$, respectively.

2) Corona Onset Measurements: Figure 6 shows the corona current for the seven different conductor types as

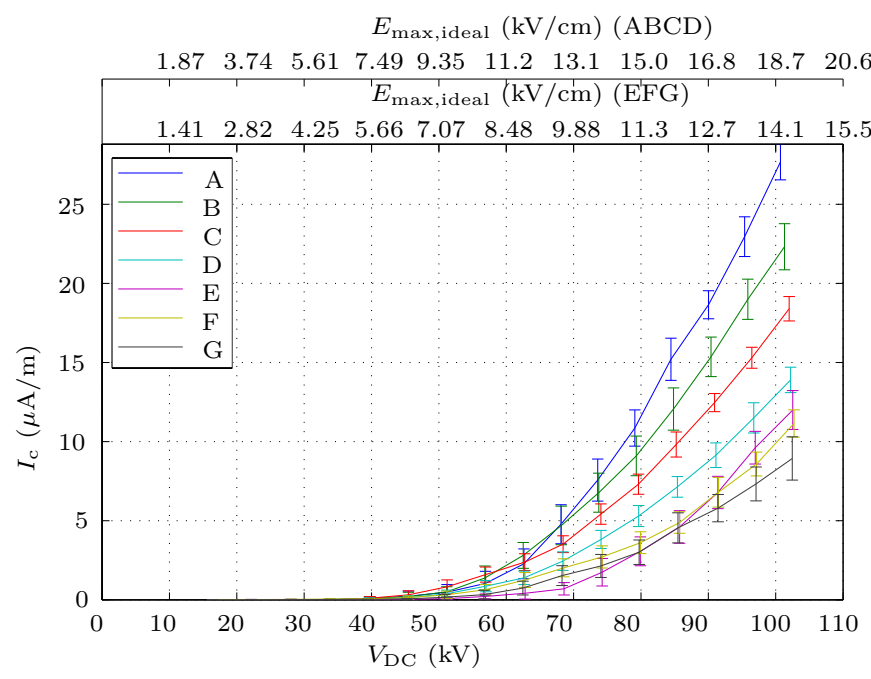

(a) Positive polarity $E_{\text {max }, \text { ideal }}(\mathrm{kV} / \mathrm{cm})(\mathrm{ABCD})$

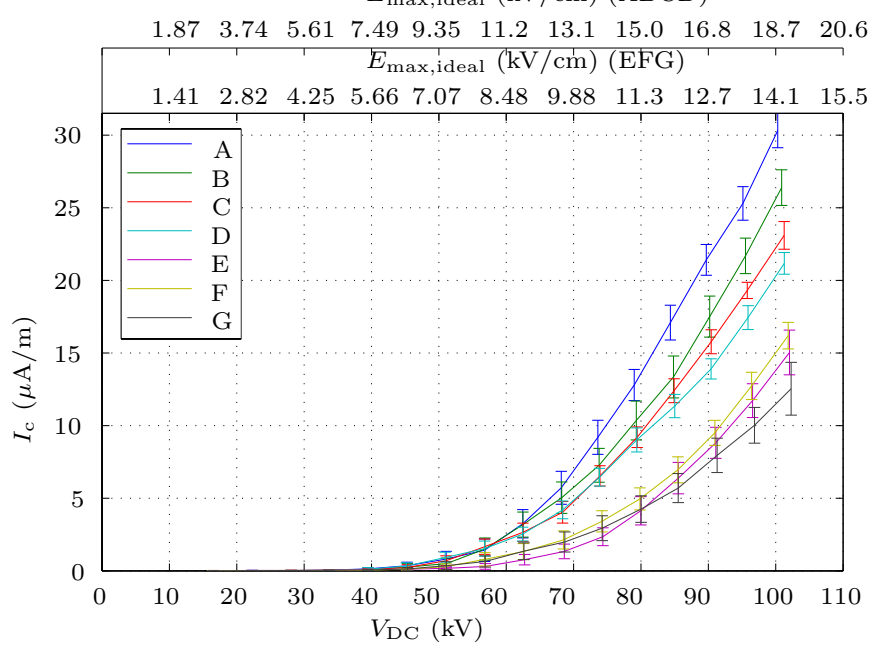

(b) Negative polarity

Fig. 6: Total corona current as a function of applied voltage $(7.5 \mathrm{~mm} / \mathrm{h}$ rain, positive polarity).

a function of applied voltage. The upper $\mathrm{x}$-axes give the corresponding maximum surface gradient, $E_{\text {max,ideal }}$, for the two different conductor diameters.

At around $100 \mathrm{kV}$, the results from the onset test reflect the relative corona performance order that was determined based on constant voltage measurements in Section IV-B1. Using this data to determine a corona onset voltage $U_{\text {on }}$ requires the selection of a somewhat arbitrary current threshold. Table III lists $U_{\text {on }}$ and the corresponding ideal corona onset surface gradient, $E_{\text {max,ideal,on, based on a }}$ threshold of $2.5 \mu \mathrm{A} / \mathrm{m}$ (a lower threshold was chosen compared to the bundle conductor measurements because the total corona current scales with the number of subconductors). Depending on the threshold as well as the instrument sensitivity and voltage step height, different values could result. 
TABLE III: Onset voltage and gradient of different conductor types.

\begin{tabular}{ccccc} 
Label & $V_{\text {on }}(+)$ & $E_{\text {max,ideal,on }}(+)$ & $V_{\text {on }}(-)$ & $E_{\max , \text { ideal,on }}(-)$ \\
\hline \hline A & 68.1 & 12.7 & 62.5 & 11.7 \\
B & 62.5 & 11.7 & 62.5 & 11.7 \\
C & 68.4 & 12.8 & 62.5 & 11.7 \\
D & 74.1 & 13.8 & 62.5 & 11.7 \\
E & 79.9 & 11.3 & 80 & 11.3 \\
F & 74.2 & 10.5 & 74.2 & 10.5 \\
G & 79.7 & 11.3 & 74.2 & 10.5
\end{tabular}

\section{Discussion}

1) Constant Voltage Measurements: The significant difference in total corona current between conductor A and $\mathrm{G}$ is presumably the combined effect of lower surface field strength due to the larger conductor diameter, different background field strength $E_{\text {max strands }}$ and different wetting behavior of the conductor surfaces that leads to a different $E_{\text {max,real }}$.

The observed reduction of the total corona current due to larger conductor diameters is not surprising and the order of magnitude of this effect can be explained by a lowering of $E_{\text {max,ideal }}$ of approximately $25 \%$ compared to conductors A through D. However, if corona performance of existing lines needs to be improved, changing to larger conductors may not be permissible due to mechanical limits of towers and fittings. In such cases, changing to conductors with special surface characteristics could be an option.

The reductions due to sand-blasting and the use of Zprofiled conductors are likely to be principally based on the same physical reasons that were discussed for the reductions on AC conductors in Section II-D. In the Z-profiled conductors, the smoother outer profile is likely to lead to a lower background electric surface field, $E_{\max \text {,strands }}$, which is likely to further contribute to lower corona losses. Further research is necessary, however, to fully understand the underlying physical reasons.

It stands out that the benefits of sand-blasting and using Z-profiled conductors are significantly more pronounced for the thinner conductors compared to their larger diameter counterparts. This could be explained by the previously mentioned theory that differences in corona current due to different wetting behavior increase in significance with an increase in the surface gradient.

An important question that remains is how differences in the surface type affect other corona effects, in particular audible noise. As [1] showed, there is a correlation between the geometric characteristics of water drops and DC corona pulse amplitudes and radio noise. In the wake of a rainfall, for example, decreases in the drop size were shown to lead to increases in the radio noise and differences in the subjective perception of audible noise. Over the same period, however, total corona currents decreased. There is thus the possibility that surface types which are advantageous from a total corona current perspective may be unfavorable from an audible noise point of view.
2) Corona Onset Measurements: The determined values of $E_{\text {max,idealon }}$ are fairly similar in magnitude for all conductor types. The values for negative polarity are in general slightly lower than those for positive polarity, which is congruent with theoretical considerations and experimental evidence [18], [1], [33].

The key finding of this experiment is, however, that differences in $E_{\text {max,ideal,on }}$ cannot be used as a predictor of the difference observed in the corona magnitude at higher voltages (c.f. Section IV-B1). In the case of the negative polarity results, for example, the value of $E_{\max , \text { ideal,on }}$ is identical for conductors $\mathrm{A}$ through $\mathrm{D}$ but their VI characteristics begin to deviate significantly at higher voltages and differences of nearly $30 \%$ were observed for realistic surface gradients of around $25 \mathrm{kV} / \mathrm{cm}$ (c.f. Figure $5)$.

The V-I shape of conductor E (Figure 6) stands out in that it initially displays the lowest corona activity of all conductor types but for higher voltages approaches or even exceeds those of conductor F. This indicates that the surface type may not only shift the V-I curves up and down but can also affect their shape.

3) Corona current as function of maximum surface gradient: Another way of considering the data from the onset tests is to plot the corona intensity as a function of $E_{\text {max,ideal }}$. This is particularly interesting for a direct comparison of the $22 \mathrm{~mm}$ and $32 \mathrm{~mm}$ diameter versions of the same conductor type. Results of this investigation are presented in Figure 7 for conductor pairs A\&E, C\&F and D\&G. It is evident that for all three pairs, the $32 \mathrm{~mm}$ version shows a higher corona current for the same value of $E_{\text {max,ideal }}$.

One possible explanation for this is the deviation between the maximum surface gradient that actually occurs, $E_{\text {max,real }}$ and the ones presented in Figure 7 . The maximum surface gradient in reality occurs on the tip of suspended rain drops. Assuming a similar average drop size for the small and large diameter conductors, the difference in $E_{\text {max }}$,real between the two different conductor sizes would actually be smaller, i.e. the curves in Figure 7 would move closer together. A second reason could be the increased collection of water caused by the larger projected area of conductors E through G. A larger diameter could have a similar effect as an increase in rain intensity, which has been linked to higher corona currents, as shown in Section III.

\section{Conclusion and Outlook}

\section{A. Impact of Rain Intensity}

The very large difference between corona currents of dry (and perfectly clean) conductors and those at the lowest rain intensity of $3.6 \mathrm{~mm} / \mathrm{h}$ indicate an almost steplike increase of the corona current as soon as there is any rain at all. The presented results indicate that increases of rain intensity above this value tend to lead to relatively small additional increases in the total corona current. The fact that not all measurements matched the 


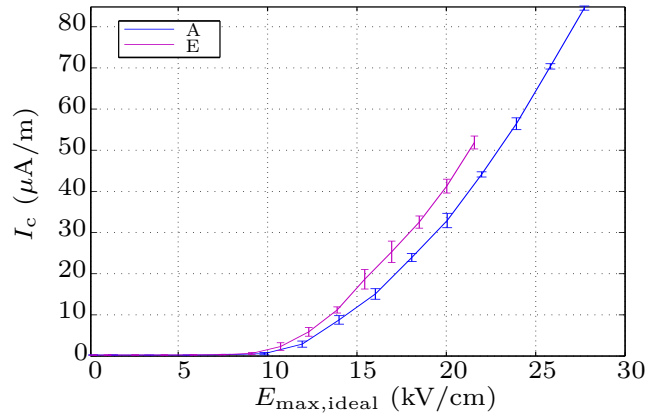

(a) Pair A and E

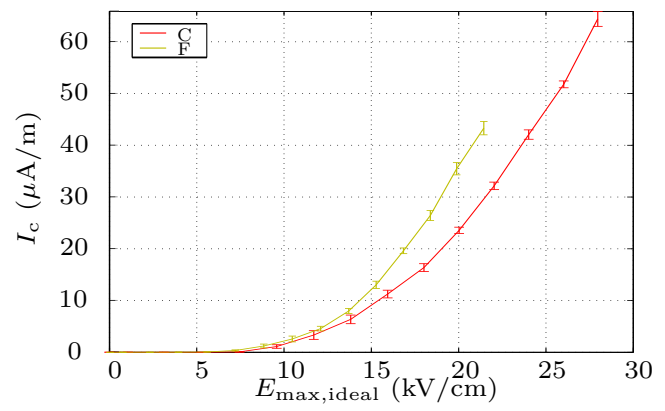

(b) Pair C and F

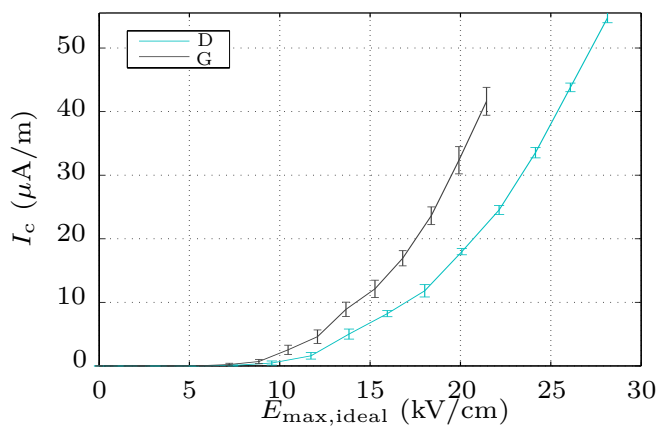

(c) Pair D and G

Fig. 7: Total corona current as a function of maximum conductor surface gradient $(7.5 \mathrm{~mm} / \mathrm{h}$ rain, positive polarity $)$.

positive correlation is an indication of certain limitations and uncertainties of the measurement procedure. Slow changing stochastic variations of corona currents even after the 10 minute pause between intensity changes may have occurred. Measurements could be improved by longer adjustment phases as well as longer measurement periods.

The corona onset voltage was shown to be independent of the rain intensity within the tested range.

\section{B. Impact of Conductor Type}

An increase in the conductor diameter from $22 \mathrm{~mm}$ to $32 \mathrm{~mm}$ was shown, on average, to lead to reductions in the total corona current of $36 \%$ (for the same voltage). A reduction of this order of magnitude was to be expected due to the decrease in the conductor surface gradient. Nevertheless, for the same $E_{\text {max }}$,ideal, larger conductors showed higher corona currents than their thinner counterparts. The positive effect of a lower surface gradient may hence be partially compensated by increased water collection on larger conductors. Furthermore, the actual maximum field strength at the tip of water drops, $E_{\text {max,real }}$, may actually differ less than $E_{\text {max }}$ ideal .

A very significant reduction was also observed with Zprofiled conductor strands compared to types with round outer strands. For $22 \mathrm{~mm}$ diameter conductors the mean reduction was determined to be $27 \%$. The use of sandblasted conductors, in comparison, lead to a lower mean reduction of $12 \%$ (considering $22 \mathrm{~mm}$ diameter conductors only). The underlying physical reason for these reductions are presumably differences in the wetting behavior. Further in-depth investigations are currently in progress.

Ground level ion current densities and ion currents collected at nearby conductors (for example AC phases of neighboring $\mathrm{AC}$ transmission systems) depend directly on the charge generation at HVDC conductors. The observed reductions in total corona loss current are therefore expected to lead to similar reductions in these related effects.

Finally, the presented results lead to implications for ion-flow simulation tools. Most of these tools base the rate of charge injection on the difference between the spacecharge-free surface electric and an empirically (or directly experimentally) determined onset field strength, $E_{\text {on }}[35]$, [36], [37], [38]. This paper showed that while there is no measurable difference in the $E_{\text {on }}$ for different conductor types, their subsequent V-I characteristics differ significantly with differences in the corona current of nearly $30 \%$ at realistic surface gradients. Ion flow simulation tools based on the described method are currently not capable of reproducing these differences. In all existing frameworks, a unique value of $E_{\text {on }}$ leads to a unique V-I characteristic.

\section{REFERENCES}

[1] M. Akazaki, "Corona Phenomena from Water Drops on Smooth Conductors under High Direct Voltage," IEEE Transactions on Power Apparatus and Systems, vol. 84, no. 1, pp. 1-8, Jan. 1965.

[2] F. Hirsch and E. Schafer, "Progress Report on the HVDC Test Line of the $400 \mathrm{kV}$-Forschungsgemeinschaft: Corona Losses and Radio Interference," IEEE Transactions on Power Apparatus and Systems, vol. PAS-88, no. 7, pp. 1061-1069, Jul. 1969.

[3] G. Johnson, "Electric Fields and Ion Currents of a $\pm 400 \mathrm{kV}$ HVDC Test Line," IEEE Transactions on Power Apparatus and Systems, vol. PAS-102, no. 8, pp. 2559-2568, Aug. 1983.

[4] J. P. Blondin, D. H. Nguyen, J. Sbeghen, D. Goulet, C. Cardinal, P. S. Maruvada, M. Plante, and W. H. Bailey, "Human perception of electric fields and ion currents associated with highvoltage DC transmission lines." Bioelectromagnetics, vol. 17, no. 3, pp. 230-41, Jan. 1996.

[5] M. Hara, N. Hayata, and M. Akazaki, "Basic studies on ion flow electrification phenomena," Journal of Electrostatics, vol. 4, no. 4, pp. 349-365, Jul. 1978.

[6] B. A. Clairmont, G. B. Johnson, and L. E. Zaffanella, "The effect of HVAC-HVDC line separation in a hybrid corridor," Power Delivery, IEEE Transactions on, vol. 4, no. 2, pp. 1338-1350, 1989.

[7] N. Hylten-Cavallius, S. Annestrand, H. Witt, and V. Madzarevic, "Insulation Requirements, Corona Losses, and Corona Radio Interference for High-Voltage D-C Lines," IEEE Transactions on Power Apparatus and Systems, vol. 83, no. 5, pp. 500508, May 1964

[8] V. L. Chartier, S. H. Sarkinen, R. D. Stearns, and A. L. Burns, "Investigation of Corona and Field Effects of AC/DC Hybrid Transmission Lines," Power Apparatus and Systems, IEEE Transactions on, vol. PAS-100, no. 1, pp. 72-80, 1981. 
[9] K. Ramesh, T. Adhikari, S. C. Kapoor, and D. P. Gupta, "Parallel operation of $\mathrm{AC}$ and $\mathrm{DC}$ lines running on the same tower," Cigré, Paper, pp. 6-14, 1988.

[10] P. S. Maruvada and S. Drogi, "Field and ion interactions of hybrid AC/DC transmission lines," Power Delivery, IEEE Transactions on, vol. 3, no. 3, pp. 1165-1172, 1988.

[11] B. Rusek, C. Neumann, S. Steevens, U. Sundermann, K. Kleinekorte, J. Wulff, F. Jenau, and K. H. Weck, "Ohmic coupling between AC and DC circuits on hybrid overhead lines," in Cigre Auckland Symposium, Auckland, 2013.

[12] C. Neumann, B. Rusek, S. Steevens, and K. H. Weck, "Design and layout of AC-DC hybrid lines," in Cigre Auckland Symposium, Auckland, 2013.

[13] M. Heindl, M. Beltle, S. Tenbohlen, U. Sundermann, and F. Schatzl, "Betriebsverhalten von Leistungstransformatoren in Hybridnetzen," in VDE-Kongress 2012. VDE VERLAG GmbH, 2012.

[14] R. Morris, A. Morse, J. Griffin, O. Norris-Elye, C. Thio, and J. Goodman, "The Corona and Radio Interference Performance of the Nelson River HVDC Transmission Lines," IEEE Transactions on Power Apparatus and Systems, vol. PAS-98, no. 6, pp. 1924-1936, Nov. 1979.

[15] P. S. Maruvada, R. D. Dallaire, O. C. Norris-Elye, C. V. Thio, and J. S. Goodman, "Environmental Effects of the Nelson River HVDC Transmission Lines-RI, An, Electric Field, Induced Voltage and Ion Current Distribution Tests," Power Apparatus and Systems, IEEE Transactions on, vol. PAS-101, no. 4, pp. 951-959, 1982

[16] V. Chartier, "Electrical environment of the uprated Pacific NW/SW HVDC Intertie," Power Delivery, IEEE Transactions on, vol. 4, no. 2, pp. 1305-1317, 1989.

[17] J. A. Jardini, B. Bisewski, B. Zhang, C. A. Peixoto, D. Renew, D. Lee, E. Aranda, G. Johnson, H. Hammarsten, J. F. Nolasco, J. Lundquist, L. A. Cabral, M. O'Brien, M. Walker, P. S. Maruvada, S. Konzelmann, T. Shigemitsu, U. Straumann, V. Jankov, and W. H. Bailey, "Electric Field and Ion Current Environment of HVDC Overhead Transmission Lines," CIGRE, Tech. Rep. August, 2011.

[18] R. M. Morris and B. Rakoshdas, "An Investigation of Corona Loss and Radio Interference from Transmission Line Conductors at High Direct Voltages," IEEE Transactions on Power Apparatus and Systems, vol. 83, no. 1, pp. 5-16, Jan. 1964

[19] B. Bailey, "Progress Report on BPA HV DC Test Line Radio Noise and Corona Loss," IEEE Transactions on Power Apparatus and Systems, vol. PAS-86, no. 10, pp. 1141-1145, Oct. 1967

[20] E. Gehrig, A. Peterson, C. Clark, and T. Rednour, "Bonneville Power Administration's 1100-kV Direct Current Test Project: II - Radio Interference and Corona Loss," IEEE Transactions on Power Apparatus and Systems, vol. PAS-86, no. 3, pp. 278-290, Mar. 1967.

[21] M. Poland, M. Belsher, and A. Osipovich, "Bonneville Power Administration's 1100-kV Direct Current Test Project: I - Measurements and Instrumentation," IEEE Transactions on Power Apparatus and Systems, vol. PAS-86, no. 3, pp. 268-277, Mar. 1967.

[22] B. Bailey, "Test Line Experience with HVDC Overhead Transmission," IEEE Transactions on Power Apparatus and Systems, vol. PAS-89, no. 7 , pp. $1625-1634$, Sep. 1970

[23] P. Maruvada, N. Trinh, D. Dallaire, and N. Rivest, "Corona performance of a conductor bundle for bipolar HDVC transmission at $\pm 750 \mathrm{kV}$," IEEE Transactions on Power Apparatus and Systems, vol. 96, no. 6, pp. 1872-1881, Nov. 1977.

[24] P. Maruvada, R. Dallaire, P. Heroux, and N. Rivest, "Corona Studies for Biploar HVDC Transmission at Voltages Between $\pm 600 \mathrm{kV}$ AND $\pm 1200 \mathrm{kV}$ PART 2: Special Biploar Line, Bipolar Cage and Bus Studies," IEEE Transactions on Power Apparatus and Systems, vol. PAS-100, no. 3, pp. 1462-1471, Mar. 1981.

[25] P. S. Maruvada, R. Dallaire, P. Heroux, and N. Rivest, "LongTerm Statistical Study of the Corona Electric Field and IonCurrent Performance of a $\pm 900-\mathrm{kV}$ Bipolar HVDC Transmission Line Configuration," IEEE Transactions on Power Apparatus and Systems, vol. PAS-103, no. 1, pp. 76-83, Jan. 1984.

[26] U. Straumann, "Berechnung und Reduktion der tonalen Geräuschemission von Hochspannungsfreileitungen," Ph.D. dissertation, ETH Zurich, 2007.

[27] T. P. Regmi and A. L. Thompson, "Rainfall Simulator for Lab- oratory Studies," Applied Engineering in Agriculture, vol. 16, no. 6, pp. 641-647, 2000.

[28] M. Semmler, U. Straumann, C. Roero, and T. Teich, "Tonale Schallemissionen von Hochspannungsfreileitungen," Bulletin $S E V$, vol. 15 , pp. 13-17, 2005 .

[29] U. Straumann and H. J. Weber, "Potential reduction of audible noise from new and aged overhead transmission line conductors by increasing their hydrophilicity," in Cigre Session, Paris, 2010.

[30] G. Taylor, "Disintegration of Water Drops in an Electric Field," Proceedings of the Royal Society A: Mathematical, Physical and Engineering Sciences, vol. 280, no. 1382, pp. 383-397, Jul. 1964

[31] M. Hara, S. Ishibe, and M. Akazaki, "Corona discharge and electrical charge on water drops dripping from DC transmission conductors - an experimental study in laboratory," Journal of Electrostatics, vol. 6, pp. 235 - 257, 1979

[32] M. Hara and M. Akazaki, "Onset mechanism and development of corona discharge on water drops dripping from a conductor under high direct voltage," Journal of Electrostatics, vol. 9, pp. 339-353, 1981.

[33] T. Zhao, "Measurement and Calculation of Hybrid HVAC and HVDC Power Line Corona Effects," Ph.D. dissertation, The Ohio State University, 1995.

[34] J. Salm and H. Tammet, "Statistical characterization of air ion mobility spectra at Tahkuse Observatory: Classification of air ions," vol. 105, pp. 9291-9302, 2000.

[35] T. Zhao, S. A. Sebo, D. G. Kasten, and S. Member, "Calculation of single phase AC and monopolar DC hybrid corona effects," Power Delivery, IEEE Transactions on, vol. 11, no. 3, pp. 1454$1463,1996$.

[36] H. Yin, J. He, B. Zhang, and R. Zeng, "Finite Volume-Based Approach for the Hybrid Ion-Flow Field of UHVAC and UHVDC Transmission Lines in Parallel," Power Delivery, IEEE Transactions on, vol. 26, no. 4, pp. 2809-2820, 2011.

[37] U. Straumann and C. M. Franck, "Ion-Flow Field Calculations of AC/DC Hybrid Transmission Lines," IEEE Transactions on Power Delivery, vol. 28, no. 1, pp. 294-302, Jan. 2013.

[38] T. Guillod, M. Pfeiffer, and C. M. Franck, "Improved Coupled Ion-Flow Field Calculation Method for AC/DC Hybrid Overhead Power Lines," IEEE Transactions on Power Delivery, vol. 29, no. 6, pp. 2493-2501, Dec. 2014.

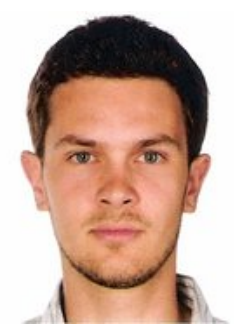

Martin Pfeiffer Martin Pfeiffer was born in Cotonou, Benin, in 1986. He received the M.Eng. degree in Engineering and Business Finance from University College London, UK, in 2008 and the M.Sc. degree in Energy Science and Technology from ETH Zurich, Switzerland, in 2012. In 2012, he joined the High Voltage Laboratory at ETH Zurich as a Ph.D. student. His main research topics are corona effects on HVDC overhead lines and their impact on potential hybrid AC/DC transmission

systems.

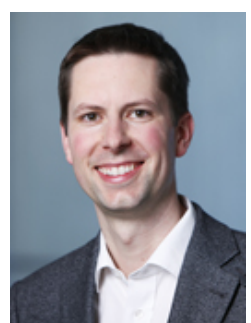

Christian M. Franck Christian M. Franck M'04-SM'11) received a diploma in physics from the University of Kiel, Germany in 1999 and the $\mathrm{Ph} . \mathrm{D}$. degree in physics from the University of Greifswald, Germany in 2003. He was with the Swiss corporate research center of ABB from 2003-2009 as a Scientist and Group Leader for gas circuit breakers and high-voltage systems. Currently, he is Assistant Professor for High Voltage Technology at the Swiss Federal Institute of Technology (ETH), Zurich, Switzerland. 